\title{
PERCEPTION OF TONAL ACCENT BY AMERICANS LEARNING JAPANESE
}

\author{
Yukihiro Nishinuma* \\ Masako Arai** \\ Takako Ayusawa***

\begin{abstract}
CNRS, Laboratoire Parole et Langage, France; nishinum@ romarin.univ-aix.fr*
Doshisha University, Kyoto, Japan; BZN00035@niftyserve.or.jp**
\end{abstract} \\ National Language Research Institute, Tokyo, Japan; ayusawa@kokken.go.jp***
}

\begin{abstract}
We studied how American subjects learning Japanese perceive tonal accents under different experimental conditions. The perceptual experiment included 3 tests, each one containing 24 words consisting of 3,4 , and 5 moras with different tonal accents. Two groups of 54 American students were asked to detect words accent. An analysis of variance showed that test, mora, and accent type factors were highly significant. Results, by accent type, suggest that the perception of tonal accent seems to be mother tongue-dependent; Accent types corresponding to English intonation patterns were preferred.
\end{abstract}

\section{INTRODUCTION}

\subsection{Aim of the study}

In speech, production and perception seem to work in parallel. However, this does not necessarily mean equal achievement in the two areas. It has been clearly shown that the perception of the sounds of foreign languages is significantly better than their production [1],[2] \& [3]. Concerning language acquisition, many works have been done for segmentals [4] \& [5], but prosodic investigation is still necessary. This aspect of perception is the concern of this study. In the following pages, we present results on the perception of Japanese tonal accent by English-speaking American adults. The picture obtained from these data is quite distinct from that for other languages.

\section{EXPERIMENT}

In order to get a better understanding of non-native learners perception of pitch variation on Japanese tonal accent, we examined the effects of (1) stimulus length and accent type, and (2) the superposition of intonation on tonal accent. Three tests were designed to study these parameters experimentally. We used 3-, 4-, and 5-mora words in combination with different tonal accents. In Test 1 , words (and phrases) uttered with a declarative intonation. In Test 2 , the words were extracted from sentences pronounced with two different intonation patterns (interrogative/ non interrogative). In Test 3 , the words were presented in a carrier sentence. The accent types are labelled from 0 to 4 , according to the absence of accent or location of the accent nucleus. Only V and CV moras were used, and the special moras were excluded.

A male native speaker from Tokyo made recordings in a soundproof room of the list of words to be used in Test 1 and Test 3. For Test 2, a female speaker read sentences like "sorewa X desu" (This is X.) or "Ja sorega X?" (Is this X?), from which the target stimulus (X) was extracted. In order to avoid a clicking sound at the point where the stimulus was truncated, the intensity was decreased by $20 \mathrm{~dB}$ over $20 \mathrm{~ms}$. For Test 3 the carrier sentence: "Watasiwa X toitta" (I said X) was used.

\begin{tabular}{|llll|}
\hline & \multicolumn{1}{c|}{ 3 moras } & \multicolumn{1}{c|}{ 4 moras } & \multicolumn{1}{c|}{5 moras } \\
\hline Accent type 0: & L-H-H $\left(\right.$ or $\left.\mathrm{H}^{*}\right)$ & L-H-H-H $($ or H*) & L-H-H-H-H $($ or H*) \\
Accent type 1: & $\mathrm{H}^{*}-\mathrm{L}-\mathrm{L}$ & $\mathrm{H}^{*}-\mathrm{L}-\mathrm{L}-\mathrm{L}$ & H*-L-L-L-L \\
Accent type 2: & L-H*-L & L-H*-L-L & L-H*-L-L-L \\
Accent type 3: & & L-H-H*-L & L-H-H*-L-L \\
Accent type 4: & & & L-H-H-H*-L \\
\hline
\end{tabular}

Table 1: The twelve accent types used in the tests. $\mathrm{L}=$ low mora, $\mathrm{H}=$ high mora $\& \mathrm{H}^{*}=$ accented high mora.

The recording was then digitized $(20 \mathrm{kHz} / 16$ bits $)$ for Fo detection. After segmentation, the signal was examined visually and aurally using a signal editor, and the best target words were selected. The output volume was normalized so that all stimuli would have a comparable auditory intensity. The stimuli were downloaded onto magnetic tapes containing the three separate tests. A presentation and explanation of the tests and some practice exercises (10 minutes) were recorded by a professional radio announcer. The two parts together were made into a cassette lasting 25 minutes.

Each stimulus was played once and then a second time one second later. This was followed by a 7-second interstimulus interval during which the subjects wrote down their answers. On the answer sheet, the words that would be heard were written in "hiragana" (mora notation) in their order of presentation. Subjects responded by placing a mark above and to the right of the mora on which they felt they heard the beginning of a pitch fall. The tests took place in a language laboratory.

The experiment was run in 1994 and 1995. The 1994 group included 29 students and the 1995 group, 25. Their mean age was 20 and all had studied Japanese in their own country for approximately two years before coming to Japan.

\section{RESULTS}

For all three tests, an analysis of variance indicated that the two subject groups did not differ significantly. On the other 
hand, the mora factor had a very significant effect $\left(\mathrm{F}_{(2,321)}=25.88, \mathrm{P}<.0001\right)$ and the test factor was also highly significant $\left(\mathrm{F}_{(2,468)}=15.48, \mathrm{P}<.0001\right)$, but post-hoc pair-wise comparisons showed that only Test 2 was significantly different from other tests.

\subsection{Test 1: Declarative context}

The overall score on Test 1 was $63 \%$, which was the best of the three tests. the highest score was obtained for stimuli without an accent nucleus (accent type 0). Accent type 2 (high tone on second mora only) came in second place. By contrast, accent types 3 and 4 were poorly perceived. The following curves illustrate these accent types(Fifure 1).
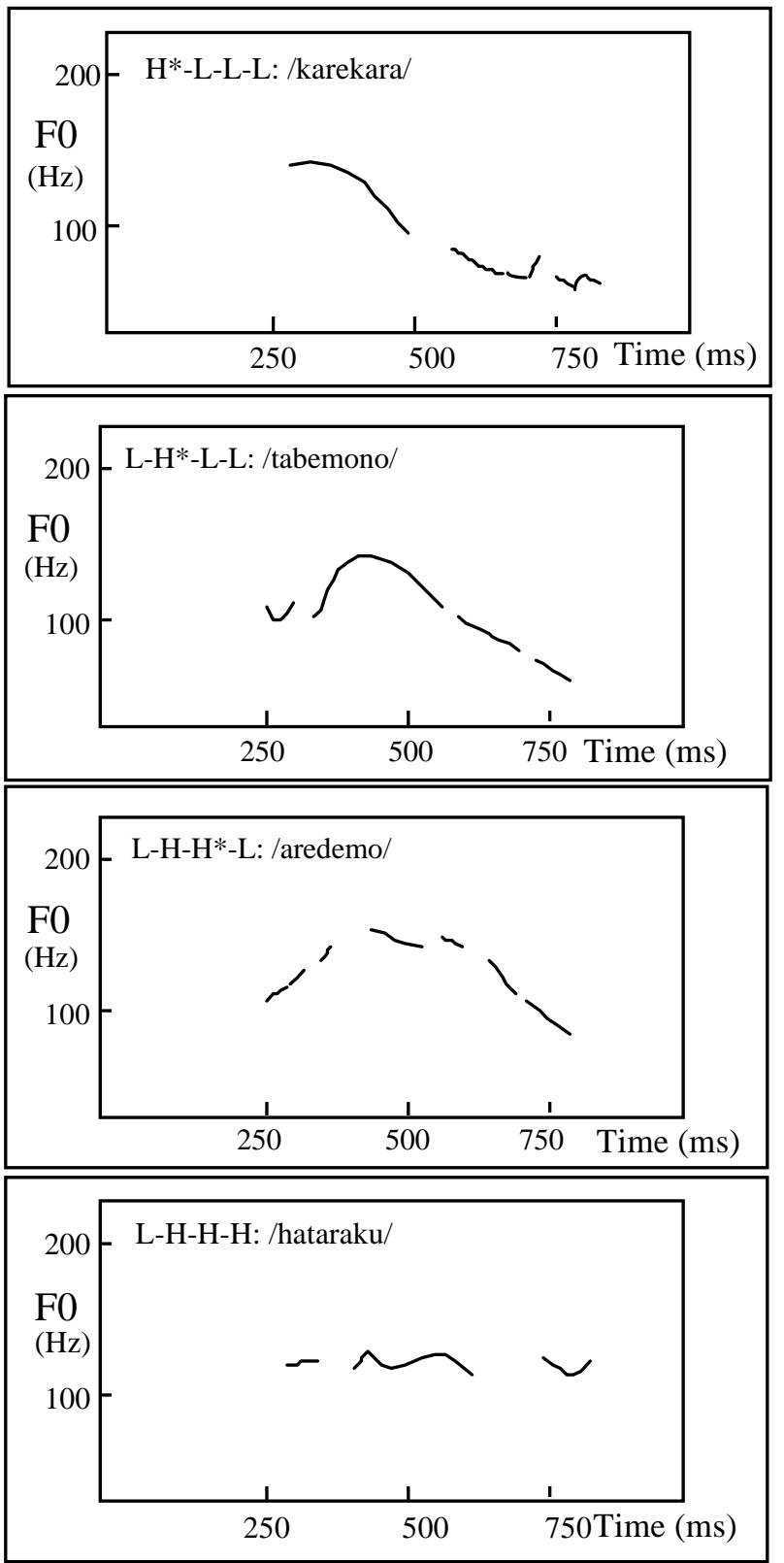

Figure 1: Fo curves for different accent types.

In an attempt to detect an underlying structure in the data, we divided the subjects into three skill levels on the basis of their overall test scores. This made three groups of 18 subjects, called Levels I, II, and III. The overall score of three tests is $42 \%$ for Level I, 59\% for Level II, and $73 \%$ for Level III. Figure 2 shows the score on Test 1 for each stimulus accent type and skill level. Despite differences across levels,

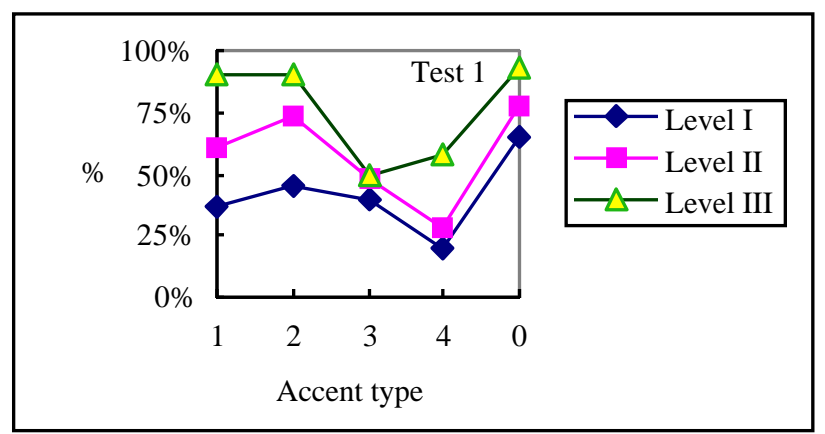

Figure 2: Correct scores by accent and skill level, Test 1.

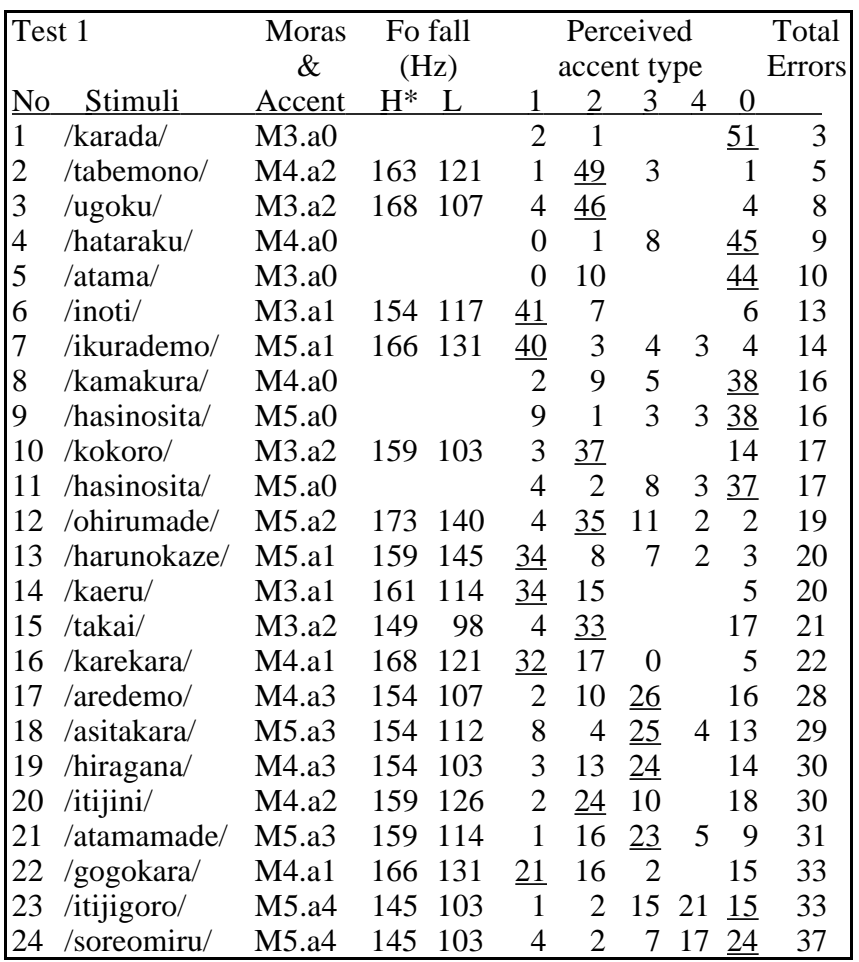

Table 2: Acoustic properties and perceived accent pattern.

The stimuli are listed in ascending order of error frequency.

Correct answers are underlined.

the same overall distribution was found. Level I subjects were successful with accent type 0 but failed on accent type 4 . Level II subjects as a whole did well on accent types 0 and 2 but obtained poor scores on accent type 4. Level III subjects had better scores than subjects at the other two levels on every type of accent but like the others, did less well on accent types 
3 and 4

In Table 2 where the stimuli are listed in ascending order of error frequency, all stimuli with accent types 0,2 and 1 are at the top of the list. Looking more closely at the stimuli and their acoustic properties, we can see the pitch difference between the high tone and the low tone is not perceived as such. There are various reasons why the pitch fall may not have been perceived. One explanation might be that accented vowels in American English are much longer than in Japanese [6] \& [7]. For native speakers of such a language, it may be difficult to perceive a distinctive phenomenon between two vowels whose duration is shorter than that of one stressed vowel in their own language.

\subsection{Test 2: Intonative context}

The overall score on Test 2 was $52 \%$, which was the lowest of the three tests. Interrogative intonation promoted correct tonal accent detection (52\%) compared to non-interrogative intonation (48\%), although this difference was not significant. However, the mora factor had a highly significant effect $\left(\mathrm{F}_{(2,321)}=25.89, \mathrm{P}<.0001\right)$. The accent type factor was also significant $\left(\mathrm{F}_{(4,255)}=114.15, \mathrm{P}<.0001\right)$.

As a whole, the same tendencies as in Test 1 were observed: accent types 0,2 , and 1 were well perceived and accent types 3 and 4 were poorly perceived, the only difference being that the order for accent types 3 and 4 was reversed. Figure 3 plots the scores for each stimulus accent type and skill level.

In Test 2, the stimuli truncated on the left had an abrupt onset, and those truncated on the right had an sharp intensity change, despite the fact that the intensity had been attenuated by $20 \mathrm{~dB}$ over $20 \mathrm{~ms}$. These effects made the speech sound very rapid and perhaps difficult to understand for an untrained ear. This may account for the poor perception of the pitch variations in Test 2.

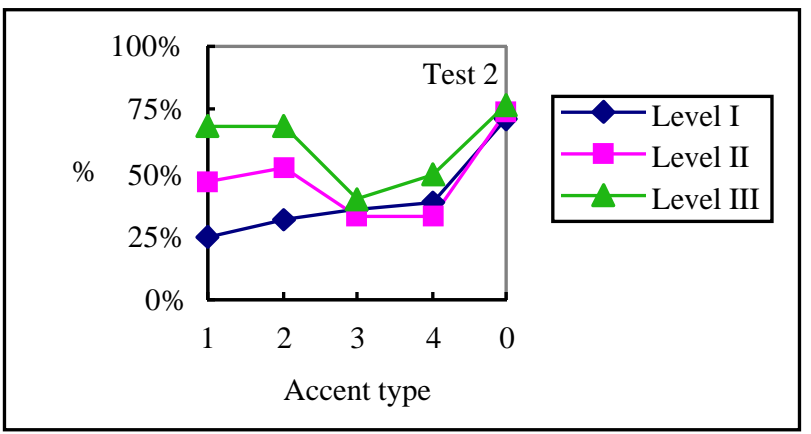

Figure 3: Corret scores by accent and skill level: Test 2.

\subsection{Test 3: Sentence context}

The overall score on this test was $59 \%$. The mora factor had a highly significant effect $\left(\mathrm{F}_{(2,150)}=104.41, \mathrm{P}<.0001\right)$, as did the accent type factor $\left(\mathrm{F}_{(4,250)}=104.44, \mathrm{P}<.0001\right)$.

On this test also, accent type 0 had the highest score, followed by accent type 2 , then 1 , and detection of accent types 3 and 4 was mediocre. Figure 4 gives the scores for each stimulus accent type and skill level.

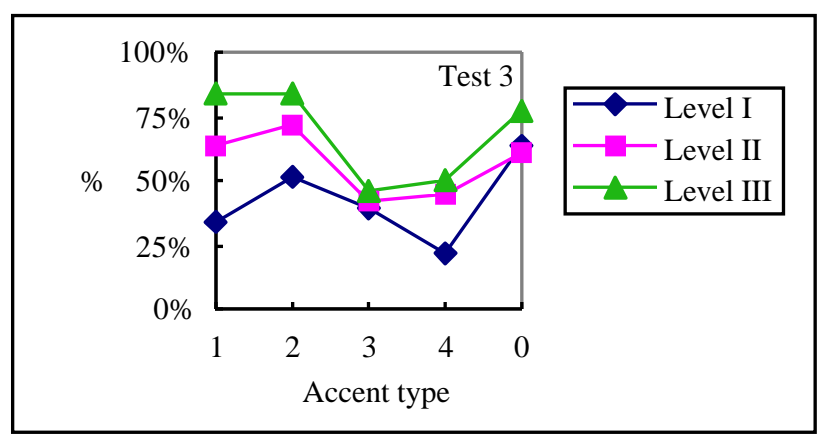

Figure 4: Correct scores by accent and skill level, Test 3.

The errors can be accounted for by the fact that the pitch fall was smaller than in the other tests. A faster speech rate was used to produce the large number of moras in the carrier sentence. This also caused a narrowing of the Fo range, so the pitch fall was not as pronounced.

\section{DISCUSSION}

Despite individual variability, some degree of overall regularity was observed here for each accent type. When compared with the results of learners from other linguistic communities, we can see that this tendency is specific to Americans. Figure 5 illustrates this by showing the results obtained for subjects from three other countries: Korea, China, and France [8], [9], [10] \& [12]. The Korean curve pertains to the results of thirty students tested in Pusan. The Chinese were 23 Pekinese students living in the Tokyo area. The 74 French subjects were students from Toulouse, Paris, and Angers.

Why then is there a general tone perception tendency specific to Americans? Theoretically, accent in English - a "stress accent" language - is marked by an increase in the degree of "force". In terms of acoustic parameters, this corresponds to a pitch peak [13], a prominent intensity, and vowel lengthening. Tonal accent in Japanese involves the opposing type of phenomenon, i.e. a more or less abrupt decrease in Fo. The difficulty experienced by English speakers is predictable.

Indeed, our analysis of the errors in relation to the acoustic properties of the stimuli pointed out that American learners looking for a pitch peak of the contour have trouble perceiving the falling pitch pattern of tonal accent.

\section{CONCLUSION}

We analyzed the perception of tonal accent by Americans learning Japanese, in order to pinpoint some general and underlying tendencies of the perceptual constraints imposed by their native language. The perception test results clearly showed that not all accent types are perceived equally well. Each type of accent appears to trigger a specific behavior which differs from that observed in native speakers of other languages. The results also showed that depending on the skill of the learners, the general tendencies encompass the subcomponents, which are linked to both the acoustic properties of the stimuli and the subjects' interpretations based on their native language. 

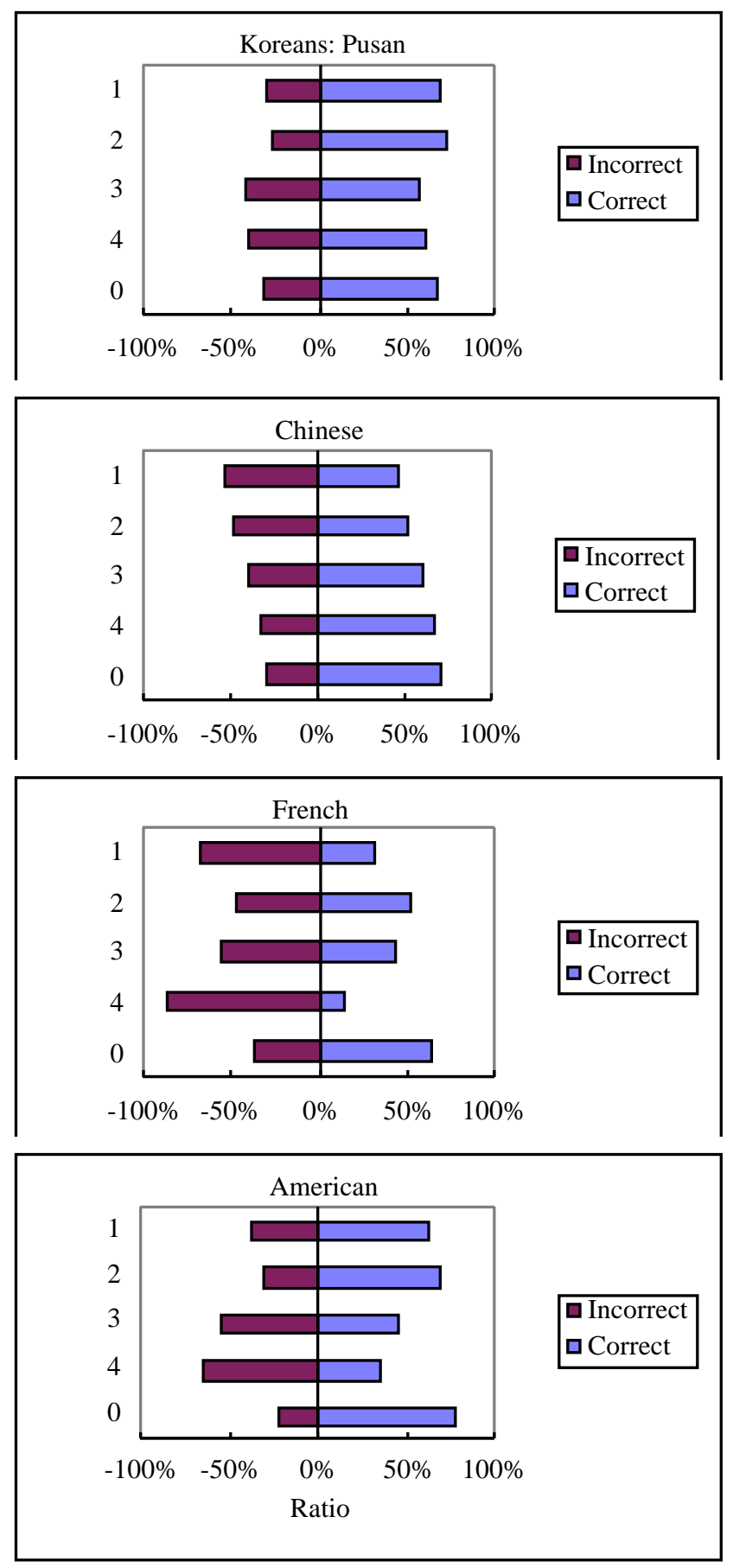

Figure 5. Comparison of four different linguistic groups [8], [9], [10] \& [12]. Y axis: accent type.

\section{REFERENCES}

1. Flege, J. E., "Factors affecting degree of perceived foreign accent in English sentenes", J. Acoust. Soc. Am. 84:70-79, 1988.

2. Borell, A., "Perception et (re)production dans l'apprentissage des langues étrangères". Revue de Phonétique Appliquée 95-96-97: 107-114, 1990.

3. Weiss, W., "Perception and production in accent training", Revue de Phonétique Appliquée 102: 69-80, 1992.

4. Llisterri, J., "Relationships between speech production and speech perception in a second language", ICPhS 95, Stockholm, vol 4, 1995, 92-99.

5. Strange, W., "Phonetics of second-language acquisition: past, present, future", ICPhS 95, Stockholm, vol 4, 76-83, 1995.

6. Beckman, M., "Segment duration and the 'Mora' in Japanese". Phonetica 39: 113-135, 1982.

7. Crystal, T. H. and House, A. S., "Segmental durations in connected speech signals: Syllabic stress", J. Acoust. Soc. Am. 83:1574-1585, 1988.

8. Lee, M.-H., "Perception of the Tokyo accent by the Korean learners -A case of the Pusan dialect speakers (1) -", J. Jpn. Lang. Lit. 4: 97-110, 1995, (in Japanese).

9. Arai, M. and Nishinuma, Y.,"Perception of the pitch patterns of the Tokyo accent by American students", PSJ 95 Annual Convention, 46-51,1995, (in Japanese).

10. Ayusawa, T., Nishinuma, Y., Lee, M.-H., Arai, M., Odaka, K. and Hoki, N., "Analysis of perceptual data on the Tokyo accent: Results from 10 language groups", JAPIC research report, 2, NLRI, Tokyo, 1995, 25-32, (in Japanese).

11. Nishinuma, Y., "How do the French perceive tonal accent in Japanese? Experimental evidence", ICSLP 94, vol 4, 1739-1742, 1994.

12. Nishinuma, Y., Ayusawa, T. and Lee, M. H., "Perception of the Tokyo accent by foreign learners of Japanese - Data from French, Chinese, and Korean students", Proc. Japan. Lang. Lit. Assoc. Korea, Pusan, 46-52, 1995.

13. Ladd, D. R., "Peak features and overall slope", Cutler, A. \& Ladd, D. R. (eds) Prosody: Models and Measurements. Springer-Verlag, Berlin, 1983, 39-52, 1983.

\section{ACKNOWLEDGEMENTS}

We would like to thank E. Hirata, N. Hoki, and C. Nakagawa for making the test tape.

This study was supported in part by a Grant-in-Aid for Scientific Research on Creative Basic Research from the Ministry of Education, Science and Culture of Japan, No. 07NP1001.

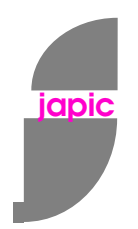

